\title{
Extreme hyperferritinemia in the setting of acute myeloid leukaemia: a case report of hemophagocytic lymphohistiocytosis
}

\author{
Damien Denimal ${ }^{* 1}$, Louise Ménégaut ${ }^{1}$, Cédric Rossi ${ }^{2}$, Laurence Duvillard ${ }^{1}$, David Masson ${ }^{1}$ \\ ${ }^{1}$ Department of Biochemistry, University Hospital Centre Dijon-Burgundy, France \\ ${ }^{2}$ Department of Clinical Hematology, University Hospital Centre Dijon-Burgundy, France \\ *Corresponding author: damien.denimal@chu-dijon.fr
}

\begin{abstract}
Introduction: Major hyperferritinemia is a rare feature in clinical laboratories associated with a wide variety of disorders, including hemophagocytic lymphohistiocytosis (HLH). The diagnosis of HLH is based on clinical and biological criteria, such as those proposed by the Histiocyte Society. However, several of these criteria are not relevant in the specific setting of hematologic malignancies.

Materials and methods: A 69-year-old male was treated for an acute myeloid leukaemia. On day 15 after the start of chemotherapy, he developed severe sepsis with high fever, low blood pressure and hepatosplenomegaly.

Results: Blood tests were marked by extreme hyperferritinemia $(191,000 \mu \mathrm{g} / \mathrm{L}$, reference range: $26-388 \mu \mathrm{g} / \mathrm{L})$ with increased (-reactive protein $(87.0 \mathrm{mg} / \mathrm{L})$ and procalcitonin $(1.94 \mu \mathrm{g} / \mathrm{L})$ and aspartate aminotransferase $\left(499 \mathrm{U} / \mathrm{L} 37^{\circ} \mathrm{C}\right)$ in the setting of chemotherapy-induced aplasia. This unusual extreme ferritinemia led to suspect HLH triggered by an invasive infection. Under intensive treatment, the clinical status improved and ferritin levels significantly decreased.

Conclusions: The diagnosis of HLH is usually based on clinical and biological criteria, mainly fever, splenomegaly, cytopenias, hypertriglyceridemia, hypofibrinogenemia, hemophagocytosis and hyperferritinemia. In this patient, the diagnosis of HLH was challenging because several criteria, such as hypertriglyceridemia, hemophagocytosis and hypofibrinogenemia, were absent. In addition, some criteria of $\mathrm{HLH}$ are not relevant in the setting of hematologic malignancy, in which fever, splenomegaly, cytopenias and elevated lactate dehydrogenase are commonly observed independently of HLH. This unusual case of extremely high ferritinemia emphasizes the important weight of the ferritin level for the diagnosis of HLH in adult patients in the setting of hematologic malignancies.
\end{abstract}

Key words: hyperferritinemia; hemophagocytic lymphohistiocytosis; hyperferritinemic syndrome

\section{Introduction}

Ferritin is an iron storage protein which plays a major role in the regulation of iron metabolism (1). Ferritinemia is routinely used to assess iron status. While mild hyperferritinemia is commonly observed in inflammatory diseases and alcoholism, major hyperferritinemia is much more unusual. Major hyperferritinemia > $50,000 \mu \mathrm{g} / \mathrm{L}$ was recently reported to be associated with a wide variety of disorders such as renal failure, hepatocellular injury, infection, hematologic malignancy, rheumatologic disorders, iron overload, haemolytic anaemia and hemophagocytic lymphohistiocytosis (HLH) (2-4). HLH is a rare but life-threatening condition, caused by genetic mutations (familial HLH) or secondary to infections, malignancies or autoimmune dis- eases (acquired HLH) $(5,6)$. HLH is characterized by an uncontrolled hyper activation of the immune system, leading to organ damages (6). Extremely high levels of ferritin may not only be a reflection of inflammation in $\mathrm{HLH}$, but may also play a role in the pathogenesis of the disease (2). A prompt and accurate diagnosis of $\mathrm{HLH}$ is crucial to start treatment as soon as possible and therefore to enhance chances of survival. To date, the diagnosis of $\mathrm{HLH}$ is based on clinical and biological criteria, such as those proposed by the Histiocyte Society in their paediatric HLH-2004 diagnostic guidelines (7). These latter specify that at least 5 of the 8 following criteria are required for the diagnosis of $\mathrm{HLH}$ : fever, splenomegaly, cytopenia affecting 2 lineages $(\mathrm{Hb}<90$ 
g/L, Plt $<100 \times 10^{9} / \mathrm{L}$, neutrophil count $<1.0 \times 10^{9} / \mathrm{L}$ ), hypertriglyceridemia and/or hypofibrinogenemia (> $3.0 \mathrm{mmol} / \mathrm{L}$ and $<1.5 \mathrm{~g} / \mathrm{L}$, respectively), hemophagocytosis (in the bone marrow aspirate, spleen or lymph node), hyperferritinemia $>500 \mu \mathrm{g} / \mathrm{L}$, impaired NK cell function and sIL2R $>2400 \mathrm{U} / \mathrm{mL}$ (7). But, in the setting of hematologic malignancies, several important criteria for the diagnosis of HLH such as cytopenias, fever or splenomegaly may be commonly found as consequences of the disease or treatments in the absence of $\mathrm{HLH}$. Here, we report a case of major hyperferritinemia, which is original because of the extremely high ferritin level, and because it emphasizes to what extent major hyperferritinemia is useful for the diagnosis of HLH in the specific setting of hematologic malignancies.

\section{Materials and methods}

\section{Subject}

A 69-year-old male with no significant medical history was admitted for chest pain to the emergency department of the University Hospital Centre Dijon-Burgundy (France). Routine biochemical and haematological blood tests were performed. Informed consent was obtained from the patient, and all procedures were in accordance with our institutional Ethics Committee and with the Declaration of Helsinki.

\section{Methods}

Ferritin, electrolytes, aspartate aminotransferase (AST), alanine aminotransferase (ALT), triglycerides, C-reactive protein (CRP) and troponin Ic were measured on Dimension Vista analyser (Siemens, Eschborn, Germany) with dedicated reagents. The ferritin assay on Dimension Vista is a sandwich chemiluminescent immunoassay with calibrators traceable to the WHO $3^{\text {rd }}$ IS $94 / 572$ standard. Complete blood cell count and haemostasis tests were performed on Sysmex XN-9000 platform (Sysmex Corporation $\mathrm{GmbH}$, Hamburg, Germany) and STA-R (Diagnostica Stago, Asnieres-surSeine, France), respectively. Procalcitonin was obtained with the Brahms Kryptor analyser (Thermo Scientific, Hennigsdorf, Germany). All instructions of manufacturers were followed.

\section{Results}

Blood tests allowed to exclude myocardial infarction based on negative troponin I (i.e. $<0.02 \mu \mathrm{g} / \mathrm{L}$ ), con- firmed 6 hours later. Upon admission, laboratory investigations revealed anaemia (haemoglobin $(\mathrm{Hb})=87$ $\mathrm{g} / \mathrm{L}$ ), thrombocytopenia (platelets (PIt) $=80 \times 10^{9} / \mathrm{L}$ ) and $20 \%$ blast cells in the white blood cell (WBC) count $\left(9.3 \times 10^{9} \mathrm{~L}\right)$. The bone marrow aspirate contained $22 \%$ blasts (99\% CD33 positive cells). All biological investigations taken together led to the diagnosis of acute myeloid leukaemia (AML) M5 with a mutation in the nucleophosmin (NPM1) gene. Then, the patient was rapidly started (day 0 ) on induction therapy with cytarabine, daunorubicin and anti-CD33 monoclonal antibody. In addition, posaconazole was administered to prevent invasive fungal infection in this patient colonized with Candida albicans. The chemotherapy-induced aplasia started on day 5 with $\mathrm{Hb}=91 \mathrm{~g} / \mathrm{L}$, neutrophils $=0.37 \times 10^{9} / \mathrm{L}$ and PIt $=21 \times 10^{9} / \mathrm{L}$.

On day 15 , the patient developed signs of severe sepsis with prolonged high fever $>39^{\circ} \mathrm{C}$ and episodes of low blood pressure, associated with hepatosplenomegaly. The clinical and laboratory features on day 15 are shown in Table 1. These laboratory test results were mainly marked by extremely high ferritinemia around 191,000 $\mu \mathrm{g} / \mathrm{L}$ (reference range: 26 - $388 \mu \mathrm{g} / \mathrm{L}$ ), confirmed the following day (compared with $1140 \mu \mathrm{g} / \mathrm{L}$ upon admission) associated with increased inflammatory markers and transaminases. HLH was primarily suspected considering the prolonged fever, hepatosplenomegaly and major hyperferritinemia in a context of predisposing underlying diseases, i.e. both $A M L$ and infection. It was suspected that an invasive fungal infection had triggered HLH in the light of repeated increases in $\beta$-D-glucan and procalcitonin levels, despite negative blood cultures in this patient preventively treated with posaconazole. Considering the life-threatening presentation, an intensive treatment was immediately started with support measures, and antifungal and antibiotic drugs, leading to a clinical improvement in the following days without use of steroids or etoposide.

On day 19 , levels of inflammatory markers, CRP (21.4 $\mathrm{mg} / \mathrm{L})$ and procalcitonin $(0.50 \mu \mathrm{g} / \mathrm{L})$, had significantly decreased. On day 20, the patient's fever and aplasia had resolved (neutrophils $=1.4 \times 10^{9} / \mathrm{L}, \mathrm{Hb}=94 \mathrm{~g} / \mathrm{L}$ ), but the severe thrombocytopenia persisted (PIt $=15 \mathrm{x}$ $\left.10^{9} / \mathrm{L}\right)$. This, however, was successfully treated with intravenous gamma globulin over the course of 4 days, suggesting that it was probably a post infection autoimmune condition. On day 23 , hepatic cytolysis markers had fallen with 87 and $201 \mathrm{U} / \mathrm{L}$ for AST and ALT, respectively. Ferritin levels gradually decreased $(33,900$ and $4280 \mu \mathrm{g} / \mathrm{L}$ on days 22 and 34 , respectively). 
TABLE 1. Clinical and laboratory features (on day 15 after the start of induction therapy).

\begin{tabular}{|c|c|c|c|}
\hline Features & Values & Reference range & Units \\
\hline \multicolumn{4}{|l|}{ Clinical features } \\
\hline Weight & 75 & - & $\mathrm{kg}$ \\
\hline Height & 1.72 & - & $\mathrm{m}$ \\
\hline Fever*t & Present & Absent & - \\
\hline Organomegaly* ${ }^{* \dagger}$ & Present & Absent & - \\
\hline Predisposing underlying disease* & Present & Absent & - \\
\hline \multicolumn{4}{|l|}{ Biochemical features } \\
\hline Sodium & 138 & $135-145$ & $\mathrm{mmol} / \mathrm{L}$ \\
\hline Creatinine & 90 & 59-104 & $\mu \mathrm{mol} / \mathrm{L}$ \\
\hline Estimated glomerular filtration rate & 63 & $>90$ & $\mathrm{~mL} / \mathrm{min} / 1.73 \mathrm{~m}^{2}$ \\
\hline AST & 499 (87 on day 23$)$ & $15-37$ & $\mathrm{U} / \mathrm{L} 37^{\circ} \mathrm{C}$ \\
\hline ALT & 246 (201 on day 23 ) & $16-63$ & $\mathrm{U} / \mathrm{L} 37^{\circ} \mathrm{C}$ \\
\hline Ferritin*t & $191,000(33,900$ on day $22 ; 4280$ on day 34$)$ & $26-388$ & $\mu g / L$ \\
\hline Lactate dehydrogenase* & NP & $132-252$ & $\mathrm{U} / \mathrm{L} 37^{\circ} \mathrm{C}$ \\
\hline Triglycerides & 1.69 & $<1.70$ & $\mathrm{mmol} / \mathrm{L}$ \\
\hline CRP & 87.0 (21.4 on day 19$)$ & $<3.2$ & $\mathrm{mg} / \mathrm{L}$ \\
\hline Procalcitonin & $1.94(0.50$ on day 19$)$ & $<0.10$ & $\mu \mathrm{g} / \mathrm{L}$ \\
\hline \multicolumn{4}{|l|}{ Haematological features } \\
\hline Haemoglobin* & 95 & $130-170$ & $g / L$ \\
\hline Platelets*† & 18 (15 on day 20$)$ & $150-450$ & $\mathrm{x} 10^{9} / \mathrm{L}$ \\
\hline White blood cells* & 1.0 & $4.0-10.0$ & $\mathrm{x} 10^{9} / \mathrm{L}$ \\
\hline Neutrophils ${ }^{\dagger}$ & 0.13 (1.4 on day 20$)$ & $1.80-7.50$ & $\mathrm{x} 10^{9} / \mathrm{L}$ \\
\hline Eosinophils & 0.0 & $0-0.8$ & $\mathrm{x} 10^{9} / \mathrm{L}$ \\
\hline Basophils & 0.0 & $0-0.2$ & $\mathrm{x} 10^{9} / \mathrm{L}$ \\
\hline Lymphocytes & 0.48 & $1.00-4.00$ & $\mathrm{x} 10^{9} / \mathrm{L}$ \\
\hline Hyperbasophilic lymphocytes & 0.02 & Absent & $\mathrm{x} 10^{9} / \mathrm{L}$ \\
\hline Monocytes & 0.0 & $0.2-1.0$ & $\mathrm{x} 10^{9} / \mathrm{L}$ \\
\hline Immature monocytes & 0.37 & Absent & $\mathrm{x} 10^{9} / \mathrm{L}$ \\
\hline $\begin{array}{l}\text { Hemophagocytosis* in bone marrow } \\
\text { aspirate }\end{array}$ & Absent & Absent & - \\
\hline \multicolumn{4}{|l|}{ Coagulation profile } \\
\hline Prothrombin time & 63 & $>70$ & $\%$ \\
\hline APTT & 1.47 & Ratio $<1.20$ & $\mathrm{sec}$ \\
\hline Fibrinogen & 4.5 & $2.0-4.0$ & $g / L$ \\
\hline D-dimer & $>4000$ & $<500$ & $\mathrm{ng} / \mathrm{mL}$ \\
\hline Lupus anticoagulant & negative & negative & \\
\hline
\end{tabular}

\section{Microbiological features}

$(1 \rightarrow 3)-\beta-D$-glucan

$\mathrm{pg} / \mathrm{mL}$

Hemocultures negative negative

*expert-based criteria for the diagnosis of $\mathrm{HLH}$ (10)

${ }^{t}$ positive (present) criteria for the diagnosis of HLH according to the HLH-2004 diagnostic guidelines (7).

CRP - C-reactive protein, AST - aspartate aminotransferase, ALT - alanine aminotransferase, APTT - activated partial thromboplastin time, NP - not performed. 


\section{Discussion}

The Histiocyte Society proposed that at least 5 of the 8 following criteria are required for the diagnosis of $\mathrm{HLH}$ : fever, splenomegaly, cytopenia affecting 2 lineages $\left(\mathrm{Hb}<90 \mathrm{~g} / \mathrm{L}, \mathrm{Plt}<100 \times 10^{9} / \mathrm{L}\right.$, neutrophil count $<1.0 \mathrm{x}$ $10^{9} / \mathrm{L}$ ), hypertriglyceridemia and/or hypofibrinogenemia (> $3.0 \mathrm{mmol} / \mathrm{L}$ and $<1.5 \mathrm{~g} / \mathrm{L}$, respectively), hemophagocytosis (in the bone marrow aspirate, spleen or lymph node), hyperferritinemia $>500 \mu \mathrm{g} / \mathrm{L}$, impaired NK cell function and sIL2R $>2400 \mathrm{U} / \mathrm{mL}$ (7). Our patient met three of these criteria namely fever, splenomegaly and hyperferritinemia, which are reported in 96,73 and $100 \%$ of HLH cases, respectively (3). Obviously, the presence of predisposing underlying disease in the patient, i.e. both malignancy and infection, which are reported in 49 and $33 \%$ of HLH cases, respectively, was an important feature for the diagnosis of acquired HLH (3).

The diagnosis of HLH was challenging in this patient for several reasons. First, several laboratory criteria from the HLH-2004 diagnostic guidelines were absent (7). In particular, there were no signs of hemophagocytosis in the bone marrow aspirate, no hypertriglyceridemia $\geq 3.0 \mathrm{mmol} / \mathrm{L}$ and no hypofibrinogenemia $\leq 1.5$ $\mathrm{g} / \mathrm{L}$, even though they are reported in 85,69 and $48 \%$ of cases of HLH, respectively (5). Second, other difficulties were due to limitations of the diagnostic criteria themselves. For instance, assessment of NK cell function, sIL2R and glycosylated ferritin are not available in routine practice, or results are returned late (8). In our case, these specialized tests could not be performed because not available in our facilities, but it reflects the everyday practice for most institutions. Moreover, there are no consensual validated diagnostic guidelines for adult HLH to date, thus leading to the use of paediatric criteria, like those from the HLH-2004 guidelines (7). Other criteria for HLH in adults were recently developed, but in the specific population of systemic juvenile idiopathic arthritis (9). Last but not least, another difficulty to diagnose HLH in our case was inherent to the specific context of hematologic malignancy. Indeed, several diagnostic criteria, such as cytopenias, fever, splenomegaly and elevated lactate dehydrogenase, are commonly found in this setting independently of HLH. Therefore, these criteria cannot be considered relevant in this context, although cytopenias, fever, organomegaly and elevated lactate dehydrogenase were considered important for the positive diagnosis of HLH for 100, 96, 92 and $75 \%$ of members of a panel of experts, respectively (10). Cytopenia affecting at least one lineage was even considered an absolute requirement for $89 \%$ of them (10).

In view of these difficulties, fever, marrow hemophagocytosis and very high ferritin level are considered as the cornerstones of the diagnosis in patients with AML (11). In our case, the high ferritin level appeared, in fact, as a preponderant criterion for the diagnosis of $\mathrm{HLH}$. Elevated ferritinemia is a well-known hallmark of HLH. A recent paper reported that mean ferritinemia on the presentation of HLH was $5316 \mu \mathrm{g} / \mathrm{L}$ (ranging from 321 to $9100 \mu \mathrm{g} / \mathrm{L}$ (3)), which is consistent with the mean value of $5140 \mu \mathrm{g} / \mathrm{L}$ reported in another adult cohort (12). Ferritinemia is a sensitive biomarker for the diagnosis of HLH. For instance, sensitivity was evaluated at $90-$ 100 and $71 \%$ for thresholds of ferritinemia of $500 \mu \mathrm{g} / \mathrm{L}$ and $1000 \mu \mathrm{g} / \mathrm{L}$, respectively $(3,7)$. In other words, normal ferritinemia has an excellent negative predictive value for the diagnosis of $\mathrm{HLH}$. On the other hand, the positive predictive value of major hyperferritinemia is a matter of debate. Schram et al. recently reported that major ferritinemia $>50,000 \mu \mathrm{g} / \mathrm{L}$ was associated with $\mathrm{HLH}$ in only $17 \%$ of cases (13). In contrast, another group considered that an extremely high ferritin level was predictive of $\mathrm{HLH}$, because it was observed in very few disorders, such as HLH and adult-onset Still's disease (2). Likewise, Allen et al. found a specificity of $96 \%$ for HLH using a ferritin threshold of $10,000 \mu \mathrm{g} / \mathrm{L}$ (14). However, this latter study was conducted in a paediatric population, in which the spectrum of underlying disorders is quite different from than in adult populations. Either way, among all disorders associated with major hyperferritinemia, the likelihood of a diagnosis of HLH seems to be higher for very high ferritin levels $(4,13)$. Indeed, Saeed et al. recently reported that among all causes of hyperferritinemia, the specificity and the positive likelihood ratio for a diagnosis of $\mathrm{HLH}$ increased in parallel of the ferritin cut off in adult patients (15).

An HScore was recently developed to estimate the individual risk of having HLH (8). This HScore takes into account three clinical and five biological weighted variables, which are easily available, i.e. triglyceridemia, AST, fibrinogenemia, cytopenias and ferritinemia. The best cut off value of the HScore was estimated at 169, corresponding to a sensitivity of $93 \%$ and a specificity of $86 \%$ for $\mathrm{HLH}$, with $90 \%$ of patients accurately classified (8). In our patient, we aimed to calculate the HScore based on features on day 15 (algorithm available online http://saintantoine.aphp.fr/score/), by considering values of haemoglobin, platelets and WBC as unknown in the model because there are not relevant 
in the context of chemotherapy-induced aplasia. In this manner, the HScore for our patient was 202, corresponding to an $89 \%$ probability of a diagnosis of $\mathrm{HLH}$. By introducing ferritinemia lower than $2000 \mu \mathrm{g} / \mathrm{L}$ (threshold proposed by the algorithm) into the model, the HScore fell very significantly from 202 to 152 , as did the probability of HLH from 89 to $28 \%$. This calculation emphasizes the important weight of the ferritin level for the diagnosis of HLH in the context in which hematologic parameters are not relevant.

In conclusion, this unusual case of extremely high ferritinemia highlights the preponderant contribution of

\section{References}

1. Tandara L, Salamunic I. Iron metabolism: current facts and future directions. Biochem Med (Zagreb) 2012;22:311-28. http://dx.doi.org/10.11613/BM.2012.034.

2. Rosário C, Zandman-Goddard G, Meyron-Holtz EG, D'Cruz $D P$, Shoenfeld $Y$. The hyperferritinemic syndrome: macrophage activation syndrome, Still's disease, septic shock and catastrophic antiphospholipid syndrome. BMC Med 2013;11:185. http://dx.doi.org/10.1186/1741-7015-11-185

3. Schram AM, Comstock P, Campo M, Gorovets D, Mullally $A$, Bodio $K$, et al. Haemophagocytic lymphohistiocytosis in adults: a multicentre case series over 7 years. Br J Haematol 2016;172:412-9. http://dx.doi.org/10.1111/bjh.13837.

4. Moore C, Ormseth $M$, Fuchs $H$. Causes and significance of markedly elevated serum ferritin levels in an academic medical center. J Clin Rheumatol 2013;19:324-8. http://dx.doi. org/10.1097/RHU.0b013e31829ce01f.

5. Ramos-Casals $M$, Brito-Zerón P, López-Guillermo A, Khamashta MA, Bosch X. Adult haemophagocytic syndrome. Lancet 2014;383:1503-16. http://dx.doi.org/10.1016/ S0140-6736(13)61048-X.

6. Janka GE, Lehmberg K. Hemophagocytic syndromes An update. Blood Rev 2014;28:135-42. http://dx.doi. org/10.1016/j.blre.2014.03.002.

7. Henter J-I, Horne A, Aricó M, Egeler RM, Filipovich AH, Imashuku S, et al. HLH-2004: Diagnostic and therapeutic guidelines for hemophagocytic lymphohistiocytosis. Pediatr Blood Cancer 2007;48:124-31. http://dx.doi.org/10.1002/ pbc.21039.

8. Fardet L, Galicier L, Lambotte O, Marzac C, Aumont C, Chahwan D, et al. Development and validation of the HScore, a score for the diagnosis of reactive hemophagocytic syndrome. Arthritis Rheumatol 2014;66:2613-20. http:// dx.doi.org/10.1002/art.38690. an extreme ferritin level to the diagnosis of HLH in adult patients in the setting of AML.

\section{Acknowledgments}

We thank laboratory technicians from departments of Biochemistry and Hematology of Dijon Burgundy University Hospital for performing the analyses, and Philip Bastable for proof reading the manuscript.

\section{Potential conflict of interest}

None declared.

9. Ravelli A, Minoia F, Davì S, Horne A, Bovis F, Pistorio A, et al. Development and initial validation of classification criteria for macrophage activation syndrome complicating systemic juvenile idiopathic arthritis. Arthritis Rheumatol 2016;68:566-76. http://dx.doi.org/10.1002/art.39332.

10. Hejblum G, Lambotte O, Galicier L, Coppo P, Marzac C, Aumont $C$, et al. A web-based delphi study for eliciting helpful criteria in the positive diagnosis of hemophagocytic syndrome in adult patients. PLoS One 2014;9:e94024. http://dx.doi. org/10.1371/journal.pone.0094024.

11. Delavigne K, Bérard E, Bertoli S, Corre J, Duchayne E, Demur $C$, et al. Hemophagocytic syndrome in patients with acute myeloid leukemia undergoing intensive chemotherapy. Haematologica 2014;99:474-80. http://dx.doi.org/10.3324/ haematol.2013.097394.

12. Rivière S, Galicier L, Coppo P, Marzac C, Aumont C, Lambotte $O$, et al. Reactive hemophagocytic syndrome in adults: a retrospective analysis of 162 patients. Am J Med 2014;127:1118-25. http://dx.doi.org/10.1016/j.amjmed.2014.04.034.

13. Schram AM, Campigotto F, Mullally A, Fogerty A, Massarotti $E$, Neuberg $D$, et al. Marked hyperferritinemia does not predict for HLH in the adult population. Blood 2015;125:154852. http://dx.doi.org/10.1182/blood-2014-10-602607.

14. Allen $C E, Y u X$, Kozinetz CA, McClain KL. Highly elevated ferritin levels and the diagnosis of hemophagocytic lymphohistiocytosis. Pediatr Blood Cancer 2008;50:1227-35. http://dx.doi.org/10.1002/pbc.21423.

15. Saeed H, Woods RR, Lester J, Herzig R, Gul Z, Monohan G. Evaluating the optimal serum ferritin level to identify hemophagocytic lymphohistiocytosis in the critical care setting. Int J Hematol 2015;102:195-9. http://dx.doi.org/10.1007/ s12185-015-1813-1. 